\title{
Energy Efficient Smart Home Automation Adoption- A Research
}

\author{
K.Rajagopal, Vaishali Mahajan, Subhasis Sen, Shishir Divkar
}

\begin{abstract}
The home appliance usage and application of the infotainment, entertainment and communication has increased alarmingly with the advent of technology. However, the energy consumed by these equipment's has also gone high. Therefore, there is an inert need for studying and planning for the energy management and exercise check and control on the energy waste at the domestic environment that occurs due to the inefficient management of the home appliance and Home automation devices. Technology has become a centre-piece of everyone's lives and is evolving in unimaginable ways. With the advancements in Internet of Things(IoT) space and ease of availability of the technology, innumerable applications of IoT are now possible beyond industries and organisations. One such application of the IoT technology is in a "Smart Home Automation System". Home Automation also referred to as "domotics" is the process in mechanizing homes using IoT that would allow owners to control lighting, temperature, music systems and other electrical appliances via use of computers or handheld devices such as smart phones or tablets. Apart from the obvious benefit of the ability to remotely control, a home automation system offers multiple benefits such as enhanced security, energy efficiency, monetary savings, comfort \& convenience and peace mind to a household that would adopt it. In line with these advantages, this paper will attempt to identify which of these factors are most relevant and important to a consumer and would lead to the adoption of home automation system and what are the factors which are of paramoun importance when it comes to energy efficient home automation.

Keywords: Energy Efficiency, Home Automation, Smart Home devices, Smart appliances, Home appliances, and Smart home technology
\end{abstract}

\section{INTRODUCTION}

Smart home automation system includes devices and appliances such as sensors, monitors, interfaces which are connected together in a network to allow automation of certain activities and devices which can be controlled remotely as well as locally in a home (Cook, 2012). Broadly, a Home automation system can be categorised into two main elements viz. Controlling devices and controllable devices. The controllable devices are usually connected to a

Revised Manuscript Received on September 10, 2019.

K.Rajagopal, Marketing department, Symbiosis Centre for Management and Human Resource Development, Symbiosis International (Deemed), Pune, Maharashtra, India.

(Email: k_rajagopal@scmhrd.edu)

Vaishali Mahajan, Marketing department, Symbiosis Centre for Management and Human Resource Development, Symbiosis International (Deemed), Pune, Maharashtra, India.

(Email: vaishali_mahajan@scmhrd.edu)

Subhasis Sen, Marketing department, Symbiosis Centre for Management and Human Resource Development, Symbiosis International (Deemed), Pune, Maharashtra, India.

(Email: subhasis_sen@scmhrd.edu)

Shishir Divkar, Marketing department, Symbiosis Centre for Management and Human Resource Development, Symbiosis International (Deemed), Pune, Maharashtra, India.

(Email: Shishir_divkar@ @scmhrd.edu) central hub or a gateway and the controlling function is performed by software on the computers or other computing devices such as smartphones or tablets (Wilson et al., 2017).

Over the last few few years, sufficient research has been performed on the home automation and the benefits of implementing the same. Below image shows research results analysis based on keyword search on Scopus for "home automation" and "benefits".

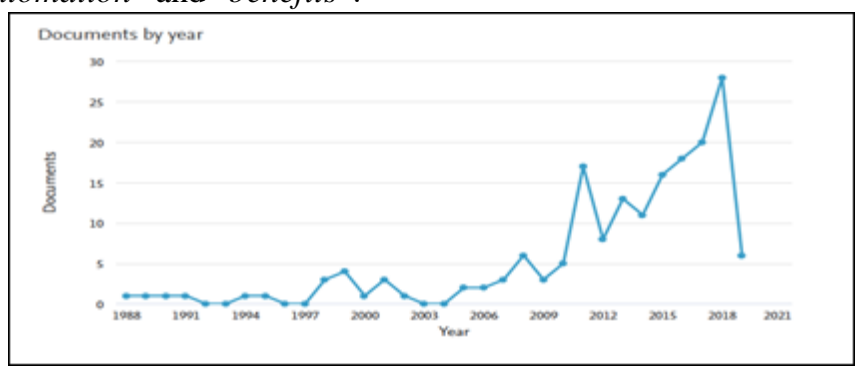

As can be seen from the graph, there is sudden increased in the number of research documents which are published since the year 2006 and has been increasing consistently since then. This indicates that there is enough interest amongst researchers to explore the area of Home Automation and understand its benefits better. In the next section we will go through the papers published to identify and evaluate the general benefits of home automation.

\section{LITERATURE REVIEW}

In today's world of smart homes, technological advancements has allowed automation of routine domestic tasks rapidly and there are multiple applications and appliances installed in homes today (Lobaccaro et al.,2016). As the use digital appliances at our homes increases, to network them together becomes a necessity and this is exactly where home automation comes to the fore (Kovatsch et al.,2010). Kovatsch et al also mention that comfort, security and efficiency are features provided by all system but the complexity is in the ability to customise these systems. Since, the home automation systems are becoming commercially viable, it offers a great opportunity for researchers to study such technology augmented homes (Mennicken S. Et al.,2012).As per Maslow hierarchy of needs, home i.e. shelter is one the basic physiological needs where as security is one safety needs both of which are essential for an individual live. Home Automation System essentially provides reliable security and control with the use of wireless technology(Ahmad et al., 2012). The impact of home automation has been far ranging from basic control,

Published By: 
security to complex applications such engird management and health monitoring (Ryan J.L., 1989). As simple and straightforward as this sounds, it has been made possible because of Internet Of Things(IoT). IoT is a system of interconnected devices, appliances, computers or any other form of hardware such as sensors with Unique Identifiers(UIDs) that have the ability to transfer data over a network(Wikipedia, Zarpelão et al., 2017). Zarpelão et al. in their study have mentioned in their study that ,IoT, today is much more refined and sophisticated. These systems rely heavily on sensors which naturally enhances capabilities of Home Automation systems by having an improved Intrusion detection System(IDS). The capabilities and opportunities offered by IoT can be amplified by adopting newer models and prototypes which would enable non-technical users and thereby making the systems user-friendly (Desolda $G$ et al.,2017). While benefits discussed above are relevant and directly related to the consumer of the home automation system, sustainability, energy efficiency and energy management are the buzz words which have become a necessity today(Pal et al.,2011). Pal et al. also suggest to achieve this a Smart meter technology can be used to implemented which would have a Home energy Information system that would provide details of household energy consumption. Such a system would not only allow the users to monitor energy consumption but also allow the user to keep the consumption under control. While every home automation system brings some benefits or all the benefits mentioned above, there are few barriers to home adoption as well. These include relatively high ownership cost, less flexible and difficult to manage(Brush et al.,2011).

\section{RESEARCH METHODOLOGY}

\section{A. Objectives}

The objective of this research is to ascertain if the factors identified from literature review would contribute to the decision making process in Home Automation adoption by a consumer. The factors that will be ascertained to be contributing to Home Automation Adoption are identified as below:

$\begin{array}{ll}\text { - } & \text { Security } \\ \text { - } & \text { Comfort \& Convenience } \\ \text { - } & \text { Energy Efficiency } \\ \text { - } & \text { Monetary savings } \\ \text { - } & \text { Price } \\ \text { B. } & \text { Hypothesis } \\ H_{0}: & \end{array}$

The factors do not contribute the home automation adoption decision making process.

\section{Ha:}

The factors do contribute to the home automation adoption decision making process.

\section{Sampling}

A simple sampling technique was used for this study by floating for the survey questionnaire to as many respondents

a possible. Data from 73 respondents was captured and is mainly categorised based on gender and age group. The intention behind the gathering the data was to understand if the factors identified from the literature review would truly contribute to the home automation adoption decision making process.

\section{Data Collection}

The data for this study was collected via a Google form survey. The survey questionnaire was mainly shared with an urban audience who are computer literate and understand the Home Automation and technology related to the same. The intention of this survey was to gauge if normal consumers are aware of the benefits that a Home Automation System offers and which of identified benefits are most important for them adopt a Home Automation System.

\section{DATA ANALYSIS, RESULTS}

The study is focused identifying if the identified to what magnitude would each of the identified factors contribute to adoption of home automation system. Below images show the results from the respondents of the survey. The male and female respondents where around $67 \%$ of the respondents were Male and remaining $33 \%$ percent were Female. Additionally, from chart 2, more than $90 \%$ of the respondents were in the age group of 20 to $40 \mathrm{yrs}$.

Based on the literature review, various benefits or factors of Home Automation were identified and the question 3 in the survey attempts to find out out which of these benefits are more important and relevant to Indian consumers. Here, $50 \%$ of the respondents feel that all factors are important and essential in a Home Automation System. Monetary benefits from Home automation are least important but $67 \%$ (i.e. $50.7 \%$ all of the above and $16.4 \%$ individual response) still feel monetary savings are important.

All questions 4 to 9 are based on a Likert scale of of 1 to 5 where the attempt is to gauge how important is each factor individually in the minds of a potential consumer.

From responses to question 4, additional security offered by any Home Automation System is very important, where almost $83 \%$ of respondents have rated it 4 and above. On similar lines, more than $85 \%$ of respondents believe that home automation system should bring Energy efficient as well.

As can be seen in, responses to Question 6, almost $84 \%$ respondents believe that Home automation system provides the comfort and convenience where as $88 \%$ believe that it should also contribute to monetary savings.

Another unique feature of the Home automation system is that it allows centralised control of electrical appliances with which a consumer would be able to turn on or off them remotely. Question 8 tries to identify the importance of the centralised controlling capability of a Home Automation System and $77 \%$ respondents feel that centralised control is very important and this factor has been rated 4 and above these $77 \%$ respondents. While functional factors and

Published By: 
benefits are very relevant and important to a consumer of a home automation system, another important and influencing factor is the price and affordability of such a solution for a consumer. So, question 9 attempts to identify how important is affordability for a consumer to adopt home automation system and almost $85 \%$ of the respondents, having responded with a value greater than 4 , feel that it is extremely important.

The purpose of this study has been to analyse if the identified factors contribute significantly to the adoption of Home Automation System. From the responses to question $10,83 \%$ of the respondents have a response of more than 4 indicating that they would adopt home automation if the benefits from questions 4 to 9 are fulfilled. The significance of the results and correlation of the factors is analysed in the sections below.

\section{Data analysis -}

Descriptive statistical values for independent variables are shown in the table below. It shows the independent variables extracted from the survey and their respective mean and Standard deviation values.

\begin{tabular}{||r|r|r|r|}
\hline \multicolumn{3}{|c|}{ Descriptive Statistics } \\
\hline & Mean & Std. Deviation & N \\
\hline Adopt_HA & 4.15 & .967 & 73 \\
Security & 4.48 & .852 & 73 \\
Energy_Efficiency & 4.12 & 1.027 & 73 \\
Comfort & 4.22 & .946 & 73 \\
Cost_Savings & 4.08 & 1.127 & 73 \\
Central_Control & 4.08 & .968 & 73 \\
Affordability & 4.27 & .990 & 73 \\
\hline
\end{tabular}

\section{Sampling Adequacy}

To validate the adequacy of the survey data, I performed the KMO and Bartletts test for the independent variables. From Descriptive statistics in Table 1, Adopt_HA is the dependent variable and the remaining are independent variables. Below is the result of the KMO test:

\section{KMO and Bartlett's test}

As, can be seen from the above table, KMO measure is 0.812 which the indicates that the sampling is adequate and can be used for factor analysis.

\section{Regression and Correlation Analysis}

From the Table 1, the Adpot_HA is the dependent variable $(y)$, the remaining are independent variables.Lets associate variables each of the factor starting with Security as x1, Energy_Efficieny as x2, Comfort as x3, Cost_Savings as $\mathrm{x} 4$, Central_Control as $\mathrm{x} 5$ and Affordability as x6.

Considering the above dependent and independent variables ,the theoretical linear equation would be formed as below:

Now that we have established a fundamental equation which can define the relationship. We can now have a statistical hypothesis.

As mentioned under the research objective,

Null hypothesis =>H0: The factors do not contribute the home automation adoption decision making process.
Then, H0 can be represented in the equation form as below:

then,

$\mathbf{H}_{0}: \mathrm{b} 1, \mathrm{b2}, \mathrm{b3}, \mathrm{b} 4, \mathrm{b5}, \mathrm{b} 6=0$
$\mathrm{H}_{\mathrm{a}}: \mathrm{b1}, \mathrm{b2}, \mathrm{b3}, \mathrm{b} 4, \mathrm{b5}, \mathrm{b} 6 \neq 0$

Alternate Hypothesis => Ha: The factors do contribute to the home automation adoption decision making process. Therefore, it can be represented in the equation form as below:

After establishing the theoretical models, we run logistical regression on the survey data. The tables below show the results of regression where we get the coefficients and their respective sig values.

Goodness-of-fit for a Linear Model

\begin{tabular}{|c|c|c|c|c|c|c|c|c|}
\hline \multicolumn{9}{|c|}{ Coetticients $^{2}$} \\
\hline \multirow[b]{2}{*}{ Model } & & \multicolumn{2}{|c|}{ Unstandarofized Coetticients } & \multirow{2}{*}{$\begin{array}{c}\text { Standardized } \\
\text { Coetticients } \\
\text { Betete }\end{array}$} & \multirow[b]{2}{*}{$t$} & \multirow[b]{2}{*}{ sig. } & \multicolumn{2}{|c|}{$95.0 \%$ Conisoence interval for } \\
\hline & & $B$ & Sted Emor & & & & Lowe Bound & Upper Bound \\
\hline 1 & (Constant) & .337 & .476 & & .700 & .481 & .613 & 1.288 \\
\hline & Sewnity & 135 & .107 & .119 & 1.269 & .209 & .078 & .348 \\
\hline & Energy_Efticiency & .065 & .108 & .069 & .599 & .551 & .151 & .280 \\
\hline & Comtort & .134 & .090 & .131 & -1.481 & .143 & .314 & .047 \\
\hline & Cost_serings & -.005 & .111 & .006 & .048 & .962 & .228 & .217 \\
\hline & Central_Control & .429 & . 098 & .430 & 4.371 & .000 & .233 & .626 \\
\hline & Aftordability & .415 & .099 & .425 & 4.188 & .000 & .217 & .613 \\
\hline
\end{tabular}

The above model defines relationship between the dependent variable $\mathrm{y}$ which is Adoption of Home Automation and the dependent variables. Here's the model summary

Pearson Correlation Coefficients

\begin{tabular}{|c|c|c|c|c|c|c|c|c|}
\hline & & Adopt HA & Seourty & $\begin{array}{c}\text { Earyy, Efician } \\
q\end{array}$ & Confort & Cost_saings & Cantral Coctiono & Alloriability \\
\hline \multirow{7}{*}{$\begin{array}{l}\text { Parson } \\
\text { Comelatica }\end{array}$} & Adopt BAA & 1.600 & .44 & .415 & .222 & .506 & .669 & .667 \\
\hline & Seanity & .484 & 1.000 & .487 & .269 & .598 & .440 & .435 \\
\hline & Energy__Fficieacy & .415 & .487 & 1.600 & .372 & .723 & 395 & .404 \\
\hline & Contort & .262 & .299 & .872 & 1.090 & .936 & .420 & .609 \\
\hline & Cos__Sarings & .596 & .508 & .728 & .386 & 1.000 & .541 & .590 \\
\hline & Central_Cotrol & .69 & .40 & .995 & .420 & .541 & 1.000 & .512 \\
\hline & Atortability & .667 & .45 & .404 & .499 & .590 & .512 & 1.000 \\
\hline \multirow[t]{7}{*}{ Sig. (1-taled } & Adoct HA & . & .000 & .000 & .088 & .000 & .909 & .000 \\
\hline & Secunty & .000 & . & .000 & .005 & .000 & .900 & .000 \\
\hline & Energy_EFiciency & .000 & .000 & . & . 001 & .000 & .900 & .000 \\
\hline & Contort & .098 & .006 & .001 & . & .000 & .900 & .000 \\
\hline & Cost_saings & .000 & .000 & .000 & .000 & . & .900 & .000 \\
\hline & Central_Control & .090 & .000 & .000 & .000 & .000 & . & .000 \\
\hline & Afoutability & .000 & .000 & .000 & .000 & .000 & .900 & . \\
\hline
\end{tabular}

Regression \& Correlation results interpretation

The regression coefficients and the corresponding sig values. As can be seen, sig values for coefficient b5 and b6 are significant (sig value $<0.05$ ) and contribute significantly to the equation and the part of null hypothesis that $\mathrm{b} 5, \mathrm{~b} 6=0$ can be rejected. Whereas, the other part of $\mathrm{H} 0$ that $\mathrm{b} 1, \mathrm{~b} 2, \mathrm{~b} 3, \mathrm{~b} 4=0$ holds true since sig value $>0.05$ and hence null hypothesis cannot be rejected where as, Ha: b5, b6 $\neq 0$ holds true

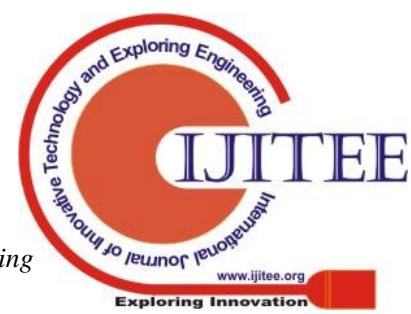


Additionally, we also need to look at the strength of the model which is summarised in the Model Summary in table 3. Since, there are multiple variables, we need to look at the

\section{Goodness-of-Fit for a Linear Model}

Adjusted R Square value which is 0.582 and it indicates the model is good enough to explain $58.2 \%$ variance in the value dependent variables when the values of independent variable changes. A value between 0.4 and 0.6 is considered to be average.

Based on the statistical analysis and as can be seen in Table 4 there is correlation between the the dependent variable "Adopt_HA" and independent variables. But, due to limited sample size the correlation has been significant and hence does not contribute significantly to the model.

\section{RESEARCH FINDINGS:}

This study has identified factors that contribute to the Home automation adoption decision making process. Below are the key finds from survey results as well as from the statistical analysis:

- If all factors are to be compared, then consumers believe that the comfort and convenience offered by the Home Automation system are the most important and relevant whereas monetary savings are least relevant or important.

- $\quad$ Security features offered by a home automation system are perceived to be the most important feature with a mean value of 4.48(refer Table 1) on a Likert scale of 1 to 5 .

- Affordability is perceived to be next most important factor with a mean value of 4.27(refer Table 1).

- Consumers also perceive the remaining factors to be important as well with a mean value ranging between 4.08 to 4.22 on Likert scale of 1 to 5 .

- There is also a high level of correlation between Home Automation Adoption and the perceived benefits (refer table 5)

- Amongst all the benefits, the factors Affordability and comfort \& convenience have the highest correlation coefficients to Home Automation Adoption.

- Results of regression also suggest that the Affordability and comfort \& convenience contribute significantly to the consumer decision on Home automation adoption.

- The Goodness-of-fit test for the linear model also indicates that the model is strong one with Adjusted $\mathrm{R}$ Squared value is 0.582 .

\section{RECOMMENDATIONS}

Based the study there can be recommendations derived for both, a prospective buyer of a Home automation system as well as the company which manufactures or produces the Home Automation System. The findings from the study has indicated that all features are essential in a Home Automation System.

For a consumer,
- Identify all the features he/she expects in a Homes Automation system from the list of features/benefits identified in this study.

- Should evaluate all features offered by a Home automation system and compare the same with other home automation system

For a Home Automation System manufacturer company,

- Ensure that the system includes most of the features listed in this paper if not all

- $\quad$ Should be make a conscious attempt to make a system that offers security and comfort and convenience while keeping cost factor under check.

\section{CONCLUSION}

All the identified factors contribute to the Home Automation adoption decision making process. But, the key feature of the Home Automation system to be able to provide centralised control of the house switches and appliances appears to be the one of the most significant factors in consumer decision making process. In addition to this, Affordability of a Home Automation system is equally important and consumer being price sensitive tend to opt for a cost effective solution. Cost of the solution has been considered as a major barrier for home automation adoption(Brush et al., 2017) and Home automation service providers should always keep this in mind.

\section{REFERENCES}

1. Peery, A. F., Dellon, E. S., Lund, J., Crockett, S. D., McGowan, C. E., Bulsiewicz, W. J., ... \& Ringel, Y. (2012). Burden of gastrointestinal disease in the United States: 2012 update. Gastroenterology, 143(5), 11791187.

2. Wilkins, E., Wilson, L., Wickramasinghe, K., Bhatnagar, P., Leal, J., Luengo-Fernandez, R., ... \& Townsend, N (2017). European cardiovascular disease statistics 2017.

3. Loiudice, A., Lobaccaro, P., Kamali, E. A., Thao, T., Huang, B. H., Ager, J. W., \& Buonsanti, R. (2016). Tailoring copper nanocrystals towards $\mathrm{C} 2$ products in electrochemical $\mathrm{CO} 2$ reduction. Angewandte Chemie International Edition, 55(19), 5789-5792.

4. Kovatsch, M., Weiss, M., \& Guinard, D. (2010, September). Embedding internet technology for home automation. In 2010 IEEE 15th Conference on Emerging Technologies \& Factory Automation (ETFA 2010) (pp. 1-8). IEEE.

5. Mennicken, S., \& Huang, E. M. (2012, June). Hacking the natural habitat: an in-the-wild study of smart homes, their development, and the people who live in them. In International conference on pervasive computing (pp. 143-160). Springer, Berlin, Heidelberg.

6. Park, S. J., Ahmad, F., Philp, A., Baar, K., Williams, T., Luo, H., ... \& Kim, M. K. (2012). Resveratrol ameliorates aging-related metabolic phenotypes by inhibiting cAMP phosphodiesterases. Cell, 148(3), 421433.

7. Felmy, A. R., Rai, D., Schramke, J. A., \& Ryan, J. L. (1989). The solubility of plutonium hydroxide in dilute solution and in high-ionic-strength chloride brines. Radiochimica Acta, 48(1-2), 29-36. 
8. Zarpelao, B. B., Miani, R. S., Kawakani, C. T., \& de Alvarenga, S. C. (2017). A survey of intrusion detection in Internet of Things. Journal of Network and Computer Applications, 84, 25-37.

9. Desolda, G., Ardito, C., \& Matera, M. (2017), Empowering end users to customize their smart environments: model, composition paradigms, and domain-specific tools. ACM Transactions on ComputerHuman Interaction (TOCHI), 24(2), 12.

10. Ko, I., Kang, H. S., Heo, H., Kim, C., Kim, G., Min, C. K., .. \& Park, B. (2017). Construction and commissioning of PAL-XFEL facility. Applied Sciences, 7(5), 479.

11. Lim, C., Medina, F., \& Langdon, M. R. (2011). U.S. Patent Application No. 29/357,805.

12. Cook, D.J., 2012. How smart is your home? Science 335 (6076), 1579-1581.

13. Abreu, Vilmar; Santin, Altair; Xavier, Alex; Lando, Alison; Witkovski, Adriano; Ribeiro, Rafael; Stihler, Maicon; Zambenedetti, Voldi; Chueiri, Ivan (2018). "A Smart Meter and Smart House Integrated to an IdM and Key-based Scheme for Providing Integral Security for a Smart Grid ICT". Mobile Networks and Applications. 23 (4): 967-981.

14. Wilson, C., Hargreaves, T., \& Hauxwell-Baldwin, R. (2017). Benefits and risks of smart home technologies. Energy Policy, 103, 72-83.

15. Lobaccaro, G., Carlucci, S., \& Löfström, E. (2016). A review of systems and technologies for smart homes and smart grids. Energies, 9(5), 348

16. Kovatsch, M., Weiss, M., \& Guinard, D. (2010, September). Embedding internet technology for home automation. In 2010 IEEE 15th Conference on Emerging Technologies \& Factory Automation (ETFA 2010) (pp. 1-8). IEEE.

17. Ahmad, A. W., Jan, N., Iqbal, S., \& Lee, C. (2011, August). Implementation of ZigBee-GSM based home security monitoring and remote control system. In 2011 IEEE 54th International Midwest Symposium on Circuits and Systems (MWSCAS) (pp. 1-4). IEEE.

\section{AUTHORS PROFILE}

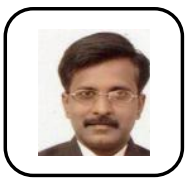

Kannan Rajagopal holds 15 years' experience of Teaching Management course both as Adjunct and Full Time Faculty in reputed Educational Institutions across the country. He has pursued his $\mathrm{PhD}$ in Marketing and $\mathrm{PhD}$ in $\mathrm{HR}$ and is associated currently with SCMHRD as a full time faculty, SIU Pune. He has presented research papers in reputed International Conferences in India and abroad. He has 2 decades of work experience in Automotive Marketing.

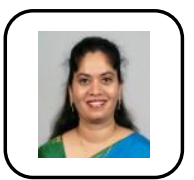

Vaishali Mahajan has 19 years of teaching Management subjects to the Masters(MBA) students. currently serves as Associate Professor and Head of the Department of Marketing Department at Symbiosis Centre for Management and Human Resource Development, Symbiosis International (Deemed), Pune. Her research interests' area includes service marketing, on line Marketing, and consumer Buying Behavior. She has presented several papers in the reputed International conferences.

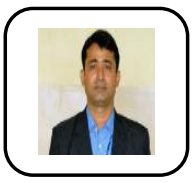

Subhasis Sen earned his B.Com. (Hons.), MBA from Jadavpur University, M.Phil. from Bharati Vidyapeeth Pune and $\mathrm{PhD}$ in Business Management from University of Calcutta and is associated with SCMHRD, Symbiosis International (Deemed University) Pune and Life Member, The Indian Econometric Society (TIES). His professional interests include Sales and Distribution Management, Services Marketing, Sports Marketing and Strategic Marketing Decisions. He has published research papers in prestigious journals of national and global repute like Survey, Indian Journal of

Marketing, Prabandhan and Global Journal of E-business \& Knowledge Management. He has around 2 decades of experience in academics, finance and IT services.

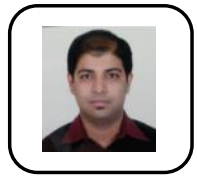

Shishir Divkar an IT Architect with more than $15 \mathrm{yr}$ of experience in building software applications for clients in various domains such as Banking, Retail and Telecom. As an individual, I am always looking for opportunities to learn something new. A problem solver by nature and I always welcome challenges which allow me to explore newer areas and in the process add value to my knowledge base. My approach to work is always result oriented where I focus mainly on what is critical for customer's as well as to my organization's success. Currently pursuing MBA in Marketing at SCMHRD. 